DOI: 10.20287/ec.n25.v1.a10

\title{
From Schutz to Dewey: communication and everyday life
}

\author{
Pedro Pinto de Oliveira \\ Universidade Federal de Mato Grosso - UFMT \\ E-mail: ppoprofegmail.com
}

\begin{abstract}
This paper presents and discusses the correlations between John Dewey's pragmatist philosophy and Alfred Schutz's phenomenological philosophy both as contributions to building up a communicational paradigm useful as an epistemological grounding and a methodological framework for Communication Sciences. We discuss the possible knowledge present in the relationship between communication and philosophy starting from the seminal notions of communication for Schutz and Dewey. These authors' ideas relate to each other in the lifeworld

or the natural environment, in the everyday life and in action. The conclusion of this paper demonstrates the application of philosophical notions to communication studies, to the perception of technology and to techniques related to technology, moving beyond a reductive and incomplete instrumental perception. Technology and techinique are all the intelligent means by both man's and natural environment's energy are directed and used to fulfill the human needs; and these are not limited to a few exterior forms nor comparatively mechanical.
\end{abstract}

Keywords: communication; philosophy; everyday; Schutz; Dewey.

\section{Introduction}

N analysis concerning the correlations and differences between Alfred Schutz's and John

Dewey's works would require an intellectual writing scope much larger than this text's. It is not our objective to compare these two philosophers' works to that extension and depth. Here we aim, first and foremost, at reflecting on and discussing the correlations of their key notions regarding communication out of the punctual election of a number of authors herein organized in this fashion: a) authors that study either Schutz or Dewey; b) authors that mention the correlations between both their philosophical schools - pragmatism and social phenomenology; c) authors that specifically mention the correlation between Schutz's and Dewey's theoretical and methodological grounds; and d) the correlations established by Schutz himself in relation with Dewey's pragmatism.

Data de submissão: 2017-10-11. Data de aprovação: 2017-12-04.

A Revista Estudos em Comunicação é financiada por Fundos FEDER através do Programa Operacional Factores de Competitividade - COMPETE e por Fundos Nacionais através da FCT - Fundação para a Ciência e a Tecnologia no âmbito do projeto Comunicação, Filosofia e Humanidades (LabCom.IFP) UID/CCI/00661/2013.

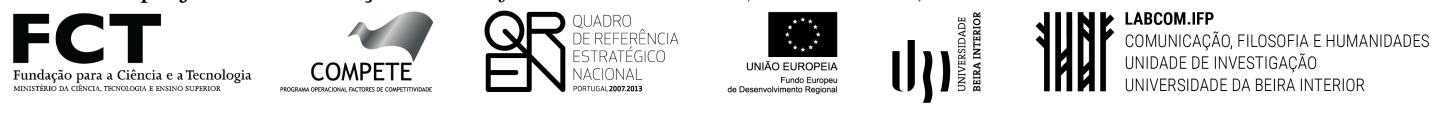


In the first part of the article, we present a brief overview of Schutz's and Dewey's careers, from their personal lives to their work; we then locate their correlations and differences, with emphasis in the former, whilst the latter, specifically, refer to the outdated and unrevised scrutiny from critics of phenomenology and pragmatism and, more interestingly for the construction of our groundings, to the what Schutz himself mentions regarding his correlations to pragmatist Dewey.

We advance in the notion of the nature of communication, according to França (2001), which concerns the scope of action, intervention and human experience in its social and symbolic dimensions; in the role of communications in constituting and articulating subjects of subjectivity and intersubjectivity, of objectivity and the ordinary world; in the relation between communication and the social realm: the founding moment in the collective life, as well as the notion of theoretical constitution and of a conceptual scheme of communication in order to understand the activity and the social organization.

Finally, we advance in the idea of an instrumental \& final communication, as conditions that must be observed in continuum for a theoretical and practical approach consistent with the complexity and entirety of the communicative process in its basic stages: interlocution among subjects, the symbolic materiality built upon and through interaction and the sociocultural context - the latter being key to Dewey's classical pragmatist line of thought and also then incorporated into Schutz's social phenomenology.

\section{The Philosophers' Careers}

In a Gofmanian manner of speaking of men and their moments, we may start the presentation of Alfred Schutz (1899-1959) and John Dewey (1859-1952) with their life as individuals. John Dewey died at the age of 93, whilst Schutz, unfortunately, passed away at the premature age of 60 . At the time Schutz was born, Dewey was well into his forties and had an established and worldwide known intellectual work. Between Schutz's birth and the release of this first well-known work at the age of 33, Die sinnhafte Aufbay der Sozialen Welt - The meaningful construction of the social world - John Dewey released 19 works.

Schutz's brief lifespan compared with Dewey's long years marks a biological distinction point between these two individuals. It is also our starting point in our presentation. In the same way, we may mark a social distinction between Schutz and Dewey by their place of birth: Austrian Schutz and American Dewey. Otherwise, by their career path: Dewey's career was dedicated to the Academia and the political activism, as he engaged several times in his long life in different movements in defense of civil rights. Schutz spent most part of this brief life juggling between academic activities, building up a solid intellectual formation, and jobs in the financial field, as we worked in a bank.

John Dewey and Alfred Schutz were two of $20^{\text {th }}$ Century's greatest intellectuals, whose ideas certainly are still relevant and influential to our thinking on the issues of the $21^{\text {st }}$ Century, including its major technological, demographic, economic and cultural changes. According to Hickman (2012), without leaving aside criticisms, it is safe to affirm there are aspects of Dewey's work that only now are coming to our attention and that will keep on bringing substantial inputs to research fields. This argumentation is obviously raised by us in relation to Schutz's work. 
John Dewey is one of the founders of the pragmatist philosophy, while Alfred Schutz is a reference in the development of a social based phenomenological philosophy. The works of these intellectuals are still influential to a plethora of authors in different fields of research due to, among other conditions, at least some common features, here enlisted: the multiplicity of covered issues; seminal ideas; theory backed by knowledge methodologies; attention to the individuals and their daily lives; as well as creativity and pertinence in some stances, which eventually place each of them ahead of their time.

According to Correia (2005), Schutz social phenomenology has been used in different areas of study, such as Communication, Philosophy, Sociology, Economics, Education Sciences, Geography, History, Esthetics, Political Theory and gender studies, among others, besides works in the areas of Nursing and Administration.

In a more recent study, Fesmire (2015) similarly raised dozens of countries and fields of study that are under Dewey's influence and the legacy: Philosophy, Psychology, Political Theory, Education, Sociology, Arts and, most recently, among others, Environment and Feminism.

\section{Of Distinctions Between Phenomenology and Pragmatism}

We start by laying out our considerations on the conceptual differences between these two philosophical currents and the punctual criticisms directed towards them:

a) Phenomenology is aimed at seeing things in the world. The object has its place in the world and is seen through its affectation potential. Emotions, differently from classical pragmatism, are triggered by something external to the subject. This philosophy incorporates basic concepts of world, life, multiple realities and worlds populated by layers, thought over empirically in relation to experimenting subjects. Criticism to phenomenology lies on the subjective propensity and on the individual's thinking only. Schutz's methodological input in social phenomenology lies in marking the subjectivity's difference, and the subjective meaning's difference, which is inherent to the conduit, whose meaning is always given by the person that acts and accredits it to his or her own conduct; on the other hand, from the researcher's subjective point of view, who affirms subjective meanings as being crucial factors in each and every communicational interaction relationship being studied.

b) Classical pragmatism offers a counterpoint to metaphysics, to the world of ideas, to abstraction that is unconnected to the natural environment. Thinking is the individual's intervention in the world; there are no dualisms - subject versus object, society versus the individuals, and nature versus culture. Pragmatism deepens this relationship. The philosophy has three main strands: anti-foundationalism, in which truth is shifting, and thought becomes a risk activity; consequentialism, in which the actions are not isolated, and are rather part of a chain, while the question lies on which act opens up possibilities; and contextualism, the strand best worked by Dewey among pragmatists. He observes that no object, practice nor product exist in isolation - they rather frame and locate the bigger picture in which they are inserted. The methodological gesture, in deweyan contextualism, is given in the act of owning the experience from an inquiring, investigating standpoint; in 
the act of observing the individual in the world, in the dayto-day action in his or her time and space. According to pragmatism, our theories must be judged by their practical value, rather then their precision in representing the world. Critics to classical pragmatism argue the method is worthy theoretically, but fails in practice. Others, more commonly, argue the method does not emphasize the notion of past as a relevant key to building up knowledge.

\section{Of Correlations: Dewey's "phenomenology"}

In a brief initial overview of Dewey's and Schutz's thought, we may mention studies on correlations, first, regarding their own philosophies in question, pragmatism and social phenomenology, respectively.

Kestenbaum (1997), in his book The Phenomenological Sense of John Dewey, brings up a notion of what would be a Dewey's phenomenological approach compared to the notions of phenomenologist Merleau-Ponty. The author points out that deweyan pragmatism would not take up an antagonistic position in its phenomenological sense, at the same time it does not put it in a position reducible to his.

Victor Kestenbaum raises the discussion about an assumption many times repeated that Dewey's pragmatism would not encompass transcendence. Far from that, affirms the author: Dewey, in approaching education, ethics, art and religion shapes a tension between natural and transcendence. This way, the pragmatic struggle of ideal meaning would take place in the intersection of visible and invisible, and of tangible and intangible.

In his work, Dewey rejects the duality between object/thought, and, fundamentally, between essence/existence. Rather, in a way he makes an approaching movement between phenomenology and his pragmatism, with a natural transcendence:

Essence is never existence, and yet it is the essence, the distilled import, of existence; the significant thing about it, its intellectual voucher, the means of inference and extensive transfer, and object of esthetic intuition. In it, feeling and understanding are one; the meaning of a thing is the sense it makes. (Dewey, 1974, p. 197)

The pragmatist philosopher admits no duality between nature and experience. Therefore, having presented themselves concretely, "things" are naturally possible and are not reducible to their mere "appearance" as opposed to reality. In his process of knowledge, Dewey highlights that objects need to be distinctive, their features need to be explicit; vague and obscure pose a limitation to knowledge. A certain tension originates from the struggle to ideal meaning, in line with Kestenbaum's hypothesis, between visible and invisible - the nature of experience reflecting and sparking deweyan experimentalism:

It is important for philosophic theory to be aware that the distinct and evident are prized and why they are. But it is equally important to note that the dark and twilight abound. For in any object of primary experience there are always potentialities which are not explicit; any object that is overt is charged with possible consequences that are hidden; the most overt act has factors which are not explicit. Strain thought as far as 
we may and not all consequences can be foreseen or made an express or known part of reflection and decision. (Dewey, 1974, p. 175)

\section{Of Correlations Between Social Phenomenology and Pragmatism}

In the field of correlations between social phenomenology and pragmatism, with its theoretical and practical contribution for research in communication, we may mention the work of Rizo (2010), which draws a connection between Alfred Schutz's and William James's core ideas. The author points out that William James' pragmatism and Alfred Schutz's phenomenology share an emphasis on what is concrete. For the former, all pragmatism's originality lies in its use of the concrete mode of seeing things. According to the author, real concretion, as referred by James, is a characteristic feature of the life world, which is the core scenario of all Schutz's thinking.

In Dewey's pragmatism and Schutz's social phenomenology, as concepts related to action, ${ }^{1} 2$ interaction and intersubjectivity are complementary by approach. In social phenomenology - in connection with elements of pragmatism - thinking and interpretations developed by the subject are carried out in a context of plans and targets as well as interests and motivations previously drafted or undergoing changes, and yet they have always been present and part of the structure of his or her day-to-day.

The notion of action is thus one of the crosscutting issues to both pragmatism and phenomenology - in the specific case of Schutz, as he incorporates Weber's comprehensive sociology - and it points to possible relations among these philosophies and knowledge in communication.

Action, as valued by these philosophical currents, is the behavior "related in the subjective manner of one who acts with reference to others' behavior", points out Rizo (2010), unfolding the understanding of reasons and beliefs to the researcher as being mobilizers of actions of interacting subjects'.

In both pragmatism and social phenomenology, the object of thinking is the mundane subject, the ordinary person, in his or her day-to-day life. According to the author, these philosophical reflections are important conceptual contributions to the concrete act of communication: interaction.

Schutz paid attention to intersubjective relations and to day-to-day interactions as the locum where subjects establish true meanings, as Rizo points out by approaching pragmatism:

Schutz asked himself how was understanding and communication possible, which structures of conscience host the meaning we grant to our actions, or what was the origin of the relationship between subjects and of sociability. Day-to-day life, here and now and whatever is concrete make up for the locum where interactions between

1. According to Joas, as explained by Pogrebinschi (2005), in order to understand the notion of action in pragmatism, it is important to understand the concept of creativity associated with it. Every human action lies in the tension between non-reflexive habitual and creativity acts. Pragmatism's creativity is generated, therefore, in the realm of problematic situations that require solutions. Action itself can be altered and reshuffled infinite times, says the author, when facing resistance throughout its course. This is where creativity lies. The creative vision in this process is our thinking, every time, which can and should be revisited by the present not as something crystallized, but rather as the root for new solutions. Imagination, according to John Dewey, is our capacity to discern opportunities that are inherent to the present, but that have not yet been carried out in the current environment. Imagination is carried out by action, which is means and ends. 
subjects take place. Similarly, James is concerned about how singular, concrete subjects establish useful meanings to carry out their actions in this world. None of them was interested in transcendental knowledge, but rather in what ordinary human beings think and do in the world of life (Rizo, 2010, p. 233).

\section{From Schutz to Dewey: dialogue between authors}

Direct correlations between Schutz's and Dewey's core notions can be found in, at least, one study, The Presence of the Past, by Rodman B. Webb (1976). The author's hypothesis is that many of Schutz's criticisms to pragmatism are unjustifiable if pointed towards Dewey's pragmatism. If Schutz's social phenomenology had a contribution from pragmatism, it certainly came from the concepts developed by Dewey.

Webb clarifies that both philosophers, in their currents of thinking, sought to better understand the relationship between person and world. The term "natural environment" in Dewey and the idea of a "world of life", to a great extent, are complementary; the phenomenological explanation of conscience as a field is linked to Dewey's consistent notion of conscience.

Schutz's idea of typification is correlated to the pragmatist notion of habit. The phenomenologist quotes Husserl in order to define the place of typifications within experience:

(...) all forms of recognition and identification, even of real objects of the outer world, are based on a generalized knowledge of the type of these objects or of the typical style in which they manifest themselves. (Schutz, 2012, p. 131)

This notion, Webb affirms, matches a subsumed part of Dewey's formulation on habit. Dewey used the daily habit in order to widely capture the propulsion potency of recurring latent trends, which is reinforced by Fesmire (2015) when he presents his definition of pragmatism's concept of habit. Habit expresses this kind of humane activity, which is influenced by previous activity in this acquired meaning; which embodies a certain ordination and systematization of minor action elements; which is projective, qualitatively dynamic and ready for ostensive manifestation; and which is operative somehow subordinately, softly, even when it is not obviously the dominant activity.

According to Webb, pragmatism's insistence in unifying subject and object within the experience perseveres in Schutz's phenomenology - the idea of relevance would make little sense if not explained in such naturalist manner.

In schutzian relevance, there are various forms of Dewey's "stages" of experience, which are further unfolded by Webb:

a) The motivational relevance is comparable to Dewey's ideas on the experience's prereflexive and qualitative elements:

b) The topic or thematic relevance worked up by Schutz finds parallel in what Dewey refers as "problem formation";

c) The interpretative relevance is similar to Dewey's explanation on research and reflexive thinking. 


\section{Of Correlations with Dewey Pointed Out by Schutz Himself}

In his work On Phenomenology and Social Relations, Schutz himself points out some correlations with Dewey's thinking. We herein recover his arguments in order to reinforce that the dialogue between the two authors is not a careless work of erudition, but rather a reflection on the affinities between Schutz's and Dewey's thinking, as well as a testimony of the potency and topicality they represent to the current challenges of research, particularly in the field of Communication studies.

Schutz's first concern is related to relevance zones, to things considered evident and defined as that sector in the world, which, in connection to either the theoretical or practical problem, raises our awareness at a particular time, though seems unlikely to require any kind of investigation.

Schutz affirms it is necessary to find our boundaries among those that go unquestioned, that are simply considered as "given" and "given the way they were presented to me" - in other words, the way either I or others who we trust have experienced it and interpreted it.

All our possible questioning for the unknown arises only within such a world of supposedly preknown things, and presupposes its existence. Or, to use Dewey's terms, it is the indeterminate situation from which all possible inquiry starts with the goal of transforming it into a determinate one. (Schutz, 2012, p. 124)

The world of daily life, for Schutz, or the natural environment, for Dewey, is, in fact, the unquestioned matrix, but rather always questionable, where our questioning is triggered and concluded. According to Schutz, Dewey understood it clearly when he described thequestioning process as the task of transforming, in either a controlled or directed manner, the undetermined situations that are either to be found within this matrix or coming out of it, conferring them warranted assertibility.

The other excerpt is related with the idea of planning and "rational choice". Schutz discusses the notion of "rational" as being "logical" in what it does not apply to the day-today level - in its traditional form, affirms the philosopher, logics cannot provide the same services we hope and need - because traditional logics, with its premises of clear and precise concepts, leaves all the attachments linking to the core stuck in the flow of unconsidered thought. As opposed to that, day-to-day thinking has a primary interest in these attachments, which link the core to the thinker's actual situation.

The social phenomenology philosopher understands we do not make day-to-day propositions with the goal of being granted formal validation in relation to a certain sphere, which can be acknowledged by others, as logics do, but rather with the sole intention of producing valid knowledge for ourselves, for our practical objectives. In this sense, and in this sense only, according to Schutz, the pragmatist principle is undeniably well grounded. Pragmatism would describe a style of day-to-day thinking, thus not elaborating a theory of knowledge.

Schutz explores the idea of planning and "rational" choice by quoting Dewey's reasoning:

As Professor John Dewey has pointed out, in our daily life we are largely preoccupied with the next step. Men stop and think only when the sequence of doing is interrupted, and the disjunction in the form of a problem forces them to stop and rehearse 
alternative ways - over, around or through - which their past experience in collision with this problem suggest. The image of a dramatic rehearsal of future action used by Professor Dewey is a very fortunate one. Indeed, we cannot find out which of the alternatives will lead to the desired end without imagining this act as already accomplished. (Schutz, 2012, p. 149)

Alfred Schutz quotes Dewey, at least, in two other of his works, Studies in Social Theory and The Problem of Social Reality, ${ }^{2}$ always seeking to incorporate the dialogue with the pragmatist philosopher. There are at least seven quotes in the former and ten quotes in the latter. The appropriations are generally organized around the following issues: a) the issue of the undetermined situation and the inability of grasping wholeness of reality in the world of life, in certain aspects only; b) the rational action within common sense's experience; Dewey's "vivid formulation" on reflection as a "dramatic rehearsal in imagination of various competing possible lines of action"; c) on questioning and doubt in terms of habit; $d$ ) on the election of objects that are within the individual's reach; the legacy left by Dewey in the field of logic by his operationalism, provided it is approached in the realm of pre-predicative experience; e) intersubjectivity as a day-to-day matter; f) the notion of a projected action's structure; and g) the world within reach and the world of daily life.

\section{Communication in Dewey and Schutz}

The notions of communication in Schutz and Dewey are complementary concerning the construction of opposite senses in the relation; in the interlocution between subjects; in a symbolic materiality established by and through interaction and in a determined sociocultural context, the idea of concretion, of the world of life for the phenomenologist, and of the natural environment for the pragmatist.

In the book Alfred Schutz's Communication Theory, ${ }^{3}$ Correia (2005) presented and discussed the locum of communication in the philosopher's thoughts. The author unveils that communication is one of the fundamental elements in Schutz's work. Communication takes place in coordinating two currents of action through symbolic means, and by structuring sociability itself. In Schutz, Correia (2005) points out, the communicative process is essential for the very existence of any social relation. Schutz highlights the intentionality's role in transmitting (our emphasis) meanings, which comes out as an essential and characteristic element of communicative processes, yet always within the relational perspective, the day-today, whatever individuals have within reach as instrumental to establishing meanings in and through interaction.

2. In the Spanish edition - El problema de la realidad social (Buenos Aires: Amorrortu, 2008) - Schutz'z quotes on Dewey can be found on pages 36, 57, 78, 87, 94, 98, 122, 166, 203, 291 and 217. In the Spanish edition of Estudios sobre teoría social (Buenos Aires: Amorrortu, 1974) - the quotes can be found on pages 79, 81, 96, 98, 123, 265 and 270.

3. In this book, Professor João Carlos Correia, besides reflecting on Schutz's works relating to communication and its role in the constitution of sociability, develops the applicability of the philosopher's core ideas in the Communication Theory by deepening the research in three realms related to the theme: "mass media analysis, particularly journalism, the relationship among public space, day-to-day communication, and multicultural dealings". 
This communication's instrumental role in transmitting is emphasized by Schutz, according to the author, when the philosopher approaches the signal used in communication that is always directed towards either an individual or an anonymous interpreter, whose origin is given by what he calls the communicator's "manipulation sphere" that is understood by the interpreter as an object. In this regard, it is interesting that Schutz highlights it is unnecessary that the interpreter's world within reach to comprise spatially the communicator's manipulation sphere, and the mentions two technological media, the telephone and the television. Correia (2005) also describes Schutz by explaining that, in more complex communicative processes, any given number of human beings and mechanical devices can be inserted in the communicative process between the original communicator and the interpreter.

Philosopher Alfred Schutz understands of the technological aspect incorporated to the communicative process in the transmission level - instrumental and connected to an end in the relational establishment of meanings - as an integral part of the process and not as something external. Besides that, he approaches another level of communication: one in which the interpretative schemes conferred to the signal by the communicator coincide substantially with that of the interpreter, in a condition provided by intersubjectivity, context and language as condition of culture, marking both differences and similarities. The sphere of language is a form of life in which the individual lives in space, time and in the relation with others. In John Dewey's metaphor, communication is the "bridge and the heart of language".

Correia (2005) approaches the relation between communication and Schutz's notions of relevance and typification, focused on the idea that the knowledge of the world, when shared, is socially derived and entails "typical" constructions, according to systems of relevance accepted by the group of interacting individuals. Put into action by communication, language would be, according to the author, a group of typifications that organize the scheme of relevances:

The human speech's conscious experience, according to Schutz, becomes the communicational process's paradigm and prototype. Typification is simultaneously the person's authentic existential speech and society's settled conventional speech. Thanks to vernacular as vulgar language, as medium, that I say "I can do it again" (Correia, 2005, p. 115).

Speech is itself instrumental and consummatory (our emphases), complementarily inviting to Dewey's reflection. According to the pragmatist, communication is an exchange that attains something desirable; it involves claim, appeal, order, instruction or request, obtaining whatever is desired at the lower cost than what personal effort would yield, provided it counts on the cooperative assistance of counterparts.

Dewey affirms communication is also an immediate intensification of life, used for its own sake. Language is always a form of action, and, in its instrumental use, it is always means of organize action to an end (our emphases), whilst, at the same time, finds in itself all the rewards of its possible consequences.

Communicative exchange imposes itself as condition to possibility of not only sharing the world, but also its understanding in a way similar to a counterpart. Participants in communication share, at least in part, according to Correia (2005) a system of relevances, a group of typificati- 
ons and a knowledge framework that "allows the capacity to interpret and express the subjective meanings that are implicit to communicative actions".

The sharing of meanings, cooperation, organization and transformation is triggered by communication, in this understanding of the schutzian notion brought about by Correia (2005). It is only possible among people, social groups and nations with the same system of relevances.

One of Schutz's and Dewey's contributions to this attempt to problematize the reflection on communication, is to observe social practices out of their respective communicative processes put in action in the day-to-day. Communication is realized as an organization of the world of life, of the individuals' constitution in intersubjectivity, yet mainly in understanding the double character of the phenomenon. Communication is as instrumental as final, and Schutz's and Dewey's contribution is in the understanding of these levels in action, always during tensions, conflicts, interdictions or in consonance and agreements, of sharing within different contexts and with the social actors acting in these contexts.

\section{Communication in times of mediatization and the technology interface}

Conforming the use of the correlations between the two philosophers' thoughts that we have already sought to articulate, Oliveira (2014) sees the schutzian notions of relevance and typification in connection to Dewey's concept of value - which is not fixed, but rather mutable and is eventually assessed in the relation - as an analytic possibility for communications phenomena in the society of mediatization. His analysis grounds lie on communication's relational paradigm.

We believe such analytical stream may contribute in understanding the communicative process' complexity and the entirety in times of mediatization, as well unfolding dynamics of power relation observed in each context, in distinct practices, uses and customs.

Therefore, we seek to reach the core of research on interactionism in society in times of mediatization concerning the study of social drive among individuals - seen as active subjects acting within social networks and groups. Symbolic games of interest and power that exist throughout the media - as a locum of confrontation - can be thus understood and analyzed by operating concepts observed herein from the perspective of social phenomenology and pragmatism (Oliveira, 2014, p. 85)

In applying the notions of both philosophical currents, social phenomenology and pragmatism, to studies in the field of communication, we may reflect upon the communicative processes in the contemporary society of mediatization by reinterpreting media beyond its mere instrumental character and technology as something rather extreme and mechanical.

This is not about acknowledging the influence of media in the task of organizing interactional processes among social fields, but instead realizing that society's constitution and functioning its practices, logics and codification schemes - are traversed and permeated by assumptions and logics of what would be called "the culture of media". Isolating contents or limiting the research to the media's instrumental character would result in admitting its existence, but rather as a minor auxiliary phenomenon. 
Media is an engendering reference in society's very way of being, as well as in processes and interactions among institutions and social actors. Hence, we no longer live in the era of media itself, but an era that establishes its own notions of reality. In this sense, society perceives and understands itself from the perspective of the media phenomenon, now enlarged beyond traditional technological devices.

Thus, mediatization is also seen as interaction, sharing and confrontation "locums" for the plethora of social groups. It is seen as life conforming without, in turn, turning into some sort of media-centered submission, in which political and power relation is realized. Communication and political research, for instance, may therefore seek, among other paths, to interpret the action of social actors, logics and ways of media languages, strengths, weaknesses or gaps in this communicative process of mediatization.

In the attempt herein made to reflect on these two philosophers' potentialities in unveiling communication's nature and role, we have established the notion of technology as means connected to an end in action, revisiting an idea brought about by Dewey. According to the author, technology means all intelligent techniques by which the energies of nature and of mankind are driven and used for the satisfaction of human needs; it cannot be constrained to some exterior and comparatively mechanical forms. He understood technology as being the continuous application of thinking, whilst seeking solutions for problems faced by mankind in its relation with nature.

The invention and use of instruments play a seminal part in consolidating meaning, because an instrument is something used as means for consequences instead of being taken directly and physically. As emphasized by the pragmatist, it is something intrinsically relational, anticipatory and foretelling.

While establishing a continuum between the notion of technology and technique within the communicative process, we may thus think of technique as the intelligent use of priorities in thought technology. At the stage of communicability, technique is the articulation of speeches put into interaction, as well as the possibility of placing us amidst the confrontations that transverse media in the society of mediatization. Technique would be out there as instrumental to thought in action, at the root of confrontations among different social groups in the communicative process of mediatization.

In other words, technology and technique, as processes and means, are thus incorporated into communication's relational paradigm, provided the instrumental and final stages are seen in connection in order to understand the communicative process' entirety in each context of action. Technologies are, according to this assumption, potency processes of thought in action, devices, means of interlocution between subjects. Technique, far from a merely instrumental point of view, is herein understood as means and ends in the articulation of speech intentionalities, in establishing a symbolic materiality put in action in and through interaction.

We compared and articulated John Dewey's and Alfred Schutz's notions in order to introduce complementary visions of communication and also to point to contributions to field researchers regarding the potency of both philosophers' thoughts when applied to formulating operating concepts, such as relevance, typification and value in analyses of communicative phenomena.

Communication is the constituting space of a reality that transcends communication itself. On the other hand, the communicational approach is an analytical perspective of social life in its daily 
overcoming. The formulation of these dialoguing Schutz's and Dewey's concepts opens up the possibility of a creative analytical approach, taking communication as starting point on social life and whatever is symbolic emerging from day-to-day interactions - in the context of our times, in the confrontations of power games and in engendered communicative strategies. In other words, creative view herein understood is the combined notion of both philosophers.

This is a new perspective, still being established. They are our first reflection about Schutz's and Dewey's connecting notions on communication and day-to-day. We understand it is a path that must further incorporate other contributions of Communication Science researchers.

\section{References}

Correia, J. C. (2005). A teoria da comunicação de Alfred Schutz. Lisboa: Livros Horizonte.

Dewey, J. (2010). Arte como experiência. São Paulo: Martins Fontes.

Dewey, J. (2009). A valoração nas ciências humanas. Campinas (SP): Autores Associados.

Dewey, J. (1974). Experiência e natureza. São Paulo: Abril Cultural (Os Pensadores)

Dewey, J. (1970). Liberalismo, liberdade e cultura. São Paulo: Editora da USP.

Dewey, J. (1964). Teoria da vida moral. São Paulo: IBRASA.

Dewey, J. (1959). Como pensamos. São Paulo: Companhia Editora Nacional.

Dewey, J. (1950). Lógica. Teoria de la investigación. México: Fondo de Cultura Económica.

Fesmire, S. (2015). Dewey. Oxford: Routledge.

França, V. R. V. (2001). Paradigmas da comunicação: conhecer o quê?. Ciberlegenda, Niteroi, UFF, v. 5.

Goffman, E. (1974). Frame analysis: an essay on the organization of experience. Londres: Harper and Row.

Hickman, L. (July 30, 2012). John Dewey's Legacy for the 21 Century. The Chronicle of Higher Education. Disponivel em: http://chronicle.com/article/ADamning-Portrait-of/133253/?cid= at\&utm_source=at\&utm_medium $=$ en.

Hook, S. (2000). John Dewey. Semblanza intelectual. Espanha, Barcelona: Paidós.

Kestenbaum, V. (1977). The Phenomenological Sense of John Dewey. Habit and Meaning. New Jersey: Humanities Press.

Oliveira, P. P. (2014). Contribuicoes do pragmatismo e da fenomenologia social para um roteiro de análise da globalidade do processo comunicativo midiatizado. In B. D. Moreira, Interfaces sociais e textualidades midiáticas. Cuiaba, MT: EdUFMT.

Pogrebinschi, T. (2005). Pragmatismo. Teoria Social e Política. Rio de Janeiro: Relume Dumará.

Rizo Garcia, M. (2010). As contribuições do pragmatismo de William James e da fenomenologia social de Alfred Schutz a Comunicação. Matrizes: Revista do Programa de Pós-Graduação em Ciências da Universidade de São Paulo, (2), jan./jul.

Schutz, A. (2012). Sobre fenomenologia e relações sociais. Petrópolis (RJ): Vozes. 
Schutz, A. (2008). El problema de la realidad social - Escritos I. Buenos Aires: Amorrortu.

Schutz, A. (1974). Estudios sobre teoría social. Buenos Aires: Amorrortu.

Webb, R. B. (1976). The presence of the past: John Dewey and Alfred Schutz on the Genesis and Organization of Experience. University of Florida Social Sciences Monographs, n. 57, Gainesville: University Presses of Florida. 